\title{
Variable effects of crowding on Drosophila hosts of male-lethal and non-male-lethal spiroplasmas in laboratory populations
}

\author{
MERCEDES A. EBBERT* \\ Department of Biology, Yale University, New Haven, CT 06511, U.S.A.
}

\begin{abstract}
Male-lethal, maternally inherited spiroplasmas occur in four species of Drosophila, and persist in natural populations despite imperfect vertical transmission rates. In the field, larval crowding is thought to be sporadic, but occasionally intense. To determine whether crowding affects host persistence, I compared the population dynamics of infected females (hosts) under crowded conditions to those expected from data collected on uncrowded females. I estimated host fitness components and maternal transmission rates for individual females under uncrowded conditions in both the artificial host $D$. pseudoobscura (this paper) and the native host $D$. willistoni (previously reported). Spiroplasma infection had no effect on lifetime production of daughters in D. pseudoobscura; however, as with some $D$. willistoni lines, hosts may produce more of their daughters earlier in life than nonhosts. Because individual contributions to relative rates of increase calculated from these fitness data were similar for hosts and nonhosts, I expected hosts to persist in laboratory populations. Instead, three patterns were observed: rapid extinction of $D$. willistoni females infected with male-lethal spiroplasmas, slow decline or persistence of hosts (depending on initial frequency) in both $D$. pseudoobscura infected with male-lethal spiroplasmas, and $D$. willistoni infected with non-male-lethal spiroplasmas. Population dynamics, then, depend on host species and bacterial isolate. Fitness estimates change with host line in uncrowded $D$. willistoni, but host genetic background did not affect population dynamics. These and previously published results show that the interaction phenotype changes with host and parasite isolate, and that host fitness can be affected by crowding. Crowding in natural populations may therefore decrease host fitness but, in expanding populations, early reproduction in hosts may be to their advantage. Possible effects of seasonal fluctuations in population density on the fitness of infected Drosophila are discussed.
\end{abstract}

Keywords: Drosophila pseudoobscura, Drosophila willistoni, insect pathogens, male-lethal spiroplasmas, maternal inheritance, relative rates of increase.

\section{Introduction}

The spiroplasmas which infect Drosophila willistoni are among the best known examples of maternally inherited male-lethal endosymbionts. These infections occur in a wide array of insects and few (typically less than 1 per cent) or none of an infected female's sons hatch (reviewed in Ebbert, 1993). Male-lethal infections have high, but imperfect, vertical transmission rates and thus are expected to drop out of populations. Benefits of infection to host fitness and/or horizontal transmission are thought to outweigh this

*Present address: Department of Zoology, Miami University, Oxford, OH 45056, U.S.A. loss of hosts and to account for their apparent persistence in natural populations.

While benefits to host fitness are the subject of this paper, it is important to note that in most male-lethal infections, including the Drosophila-spiroplasma interaction, horizontal transmission remains a virtually unexplored and potentially crucial factor in the persistence of the endosymbionts (Ebbert, 1993). Laboratory attempts to transmit spiroplasmas by feeding (Williamson \& Poulson, 1979; but see Carvalho \& da Cruz, 1962) and by coculturing uninfected and infected stocks (Ebbert, 1991) have failed. However, horizontal transmission in the field has never been investigated and the inter-and intraspecific interactions common in Drosophila ecology (see Discussion) would make horizontal transmission likely. Horizontal transmission may 
well explain what are assumed to be very similar bacterial infections in four of the willistoni group species. In the complex of associations between mosquitos and their microsporidian endosymbionts, the only case in which horizontal transmission has been extensively investigated, horizontal transmission is crucial to endosymbiont persistence (references and review in Ebbert, 1993). However, because of their reliance on horizontal transmission and because, within a species, effects of infection on both sexes can range from benign to lethal, the mosquito infections clearly cannot be considered primarily maternally inherited or male-lethal, and so I have argued that they represent a separate class of distorter infections (Ebbert, 1993).

Because vertical transmission rates are typically well over 90 per cent in male-lethal infections, a small improvement in the number and survival of infected daughters produced by hosts (relative to the number of daughters produced by uninfected insects) can slow, even reverse, the expected loss of hosts from a population (Watson, 1960; Fine, 1978; Uyenoyama \& Feldman, 1978; Werren, 1987). Such slight increases will not restore host fitness to that of uninfected females as hosts lose all their sons. In this paper, reference to possible host benefits is limited to the small increases in female fitness sufficient to counteract loss of hosts by imperfect vertical transmission.

Discussion of possible benefits of male-lethal infections to host fitness has, to date, mainly focused on three mechanisms by which killing sons may benefit male-lethal parasites: via release of resources to hosts, avoidance of inbreeding or horizontal transmission. In the first two hypotheses, killing sons improves the fitness of their sisters, most of which are assumed to be infected, and thereby increases the number of new parasite hosts. The third mechanism (killing male or female hosts to release infective pathogens, as in the mosquito infections mentioned above) does not improve host fitness, and so is not considered further here.

The avoidance of inbreeding hypothesis suggests killing sons ensures that daughters will avoid the negative effects of sib $\times$ sib inbreeding (Shull, 1948; Werren, 1987), and assumes that (i) sib $\times$ sib inbreeding carries a significant fitness cost, and (ii) it occurs often enough to promote the fitness of individuals that avoid inbreeding. Of course, if inbreeding is costly and common, one might assume that host mechanisms to avoid this cost would evolve. Circumstantial evidence supporting this hypothesis exists (summarized by Hurst \& Majerus, 1993) but its application in any specific system is unknown.

Killing sons might also release resources to daughters (Skinner, 1985). This hypothesis assumes: (i) larval resources are limited, (ii) male death releases those resources primarily to sisters, and (iii) most sisters are pathogen hosts. Male-lethal infections in the parasitoid wasp Nasonia vitripennis clearly meet these assumptions (Skinner, 1985), and Hurst and Majerus (1993) argue that this model applies to several other infections. For example, newly hatched larvae of ladybird beetles often consume unhatched eggs. Malelethal infection in Adalia bipunctata increases the number of eggs available for sibling consumption, and so the dead sons could themselves be considered a released resource (Hurst et al., 1992, 1993). Hurst et al. $(1992,1993)$ report that the average sex ratio (percentage female) in broods of field-caught and $\mathrm{F}_{1}$ A. bipunctata is 82 per cent (from 11 females, $\mathrm{SD}=13$, range 67-100 per cent), and attribute the comparatively high proportion of surviving sons to low vertical transmission rates (estimated at 87 per cent). Thus, as a result of infection, a considerable number of eggs will be available to sibling hosts. However, if most eggs are eaten by nonhosts, or if most hosts do not eat eggs, then the benefit to parasites of killing males is reduced. Some of the resources released by the death of sons will be used by nonhost siblings: if 13 per cent of a brood is uninfected, and all male hosts die, then 23 per cent of survivors will be nonhosts. Unrelated larvae and adults can also consume these resources. The incidence of cannibalism and the impact of nonsib cannibalism is thought to vary widely with the density of both beetle and prey (aphid) populations (e.g. Banks, 1956; Mills, 1982; Osawa, 1989; Hemptinne et al., 1992). The importance of egg cannibalism will therefore vary with populations and over time. Hurst et al. (1993) have shown a small bias towards females in pupae collected over a month in an affected population; however, no direct advantage of male death to ladybird hosts in any population has been documented.

Hurst \& Majerus (1993) recently reviewed how these mechanisms may benefit parasites and concluded that 'male-killing appears to be an adaptive strategy for the microorganism in most cases' (p. 81). However, as I argue in the Discussion, the ecology of $D$. willistoni is relatively well studied and suggests that resource release and inbreeding avoidance may be unimportant or minor factors in the persistence of male-lethal infections in Drosophila. Furthermore, the existence of a non-male-lethal, maternally inherited spiroplasma infection in field populations of $D$. hydei (a cosmopoli$\tan$ species not closely related to the willistoni group, Ota et al., 1979) and the success in laboratory culture of spontaneous non-male-lethal mutants (Yamada et al., 1982; Ebbert, 1991) underscores the fact that male-lethality is not necessary to explain spiroplasma persistence. 1 aim in this paper to promote further exploration of the effects of infection on female fitness 
that are unrelated to killing sons and that may operate in addition to (or in the absence of) effects proposed for male-lethality.

While it is clear that male-lethality may be adaptive in some cases, other benefits to infection have not been sufficiently studied. Hurst \& Majerus (1993) consider effects of infection on female fitness, but conclude that available evidence indicates infection with male killers, in the absence of advantages deriving from killing males, is detrimental' (p. 82) and that if male-killing is nonadaptive, infections are 'maintained through horizontal transmission unassociated with male death' ( $p$. 91). These conclusions are open to question as the available evidence on female fitness is quite scare. In insects other than Drosophila, three studies suggest no effect of infection, three show a negative effect and one suggests a positive effect (reviewed in Ebbert, 1993). However, these studies use a limited array of techniques and/or range of host and parasite isolates to estimate female fitness. Studies of fitness in Drosophila females tend to be more comprehensive. They show that spiroplasmas affect fitness in a variety of measures and that the nature of these effects can change depending on the fitness parameter estimated and on bacterial and fly isolate used (reviewed in Williamson \& Poulson, 1979; Ebbert, 1993; see also Ebbert, 1991). None of the studies on female fitness in any male-lethal infection explores the interaction of infection with environmental variation and all are confined to the laboratory. Both benefits and detriments to host fitness, irrespective of any male-lethal trait, have been demonstrated in a wide variety of interactions between insects and haemolymph-borne microbes, including spiroplasmas and related mollicutes (reviews which cover insect-mollicute interactions include Purcell, 1982; Hammond \& Hardy, 1988; Campbell, 1989; Purcell \& Nault, 1991). Thus the range of possible effects of male-lethal endosymbionts on their hosts extends far beyond those that derive from the malelethal trait. The question of whether and how female fitness is affected by infection cannot be considered closed in any male-lethal interaction.

There is growing evidence that spiroplasmas and related bacteria affect host reproductive patterns. In some D. willistoni lines (Ebbert, 1991) infected females produce more daughters earlier in life than uninfected females, although their lifetime production of daughters is unaffected. In D. nebulosa, hosts mate 2 days earlier than uninfected females (MalogolowkinCohen \& Rodrigues-Pereira, 1975). Some Dalbulus leafhoppers infected with mollicutes have a shorter generation time than their uninfected conspecifics (Madden et al., 1984). Vega (1992) provides evidence that nonvector insects produce more offspring early in their reproductive life after feeding on spiroplasma- infected plants. In expanding populations, these shifts towards early reproduction relative to uninfected females could benefit hosts in both laboratory (Gilpin, 1974) and natural (Rosewell \& Shorrocks, 1987) populations. In five species common to natural populations of British Drosophila, Rosewell \& Shorrocks (1987) argue that the typical lifespan is only about 3 days, making early fecundity and readiness to mate extremely important fitness components.

In the experiments reported here, I assumed that crowded field conditions among Drosophila larvae or adults may affect female fitness, and so estimated host fitness under crowded laboratory conditions. Variation in the interaction's phenotype was examined earlier (Ebbert, 1991) and in this study by assessing fitness in various combinations of fly and bacterial isolates. In the previous study I reported on transmission rates and fitness components of infected $D$. willistoni females in uncrowded conditions, using both male-lethal and nonmale-lethal spiroplasmas and three inbred lines of $D$. willistoni. Here, I estimate fitness components and transmission rates in an artificial host of male-lethal spiroplasmas, $D$. pseudoobscura. Using these data, I calculate individual contributions to the relative rate of increase (Lenski \& Service, 1982) in hosts and nonhosts. These estimates suggest that neither hosts nor nonhosts should have an advantage in mixed laboratory populations unless fitness and transmission rates change with their relative frequencies or under crowded conditions. I compare these predicted dynamics to those observed in laboratory populations of two species ( $D$. willistoni and $D$. pseudoobscura) infected with both types of spiroplasmas.

\section{Materials and methods}

\section{Study organisms}

The interaction between $D$. willistoni and spiroplasmas, and the derivation of the fly and spiroplasma stocks used in this study were previously described (Ebbert, 1991) and are summarized here. Spiroplasma infections result in all-female broods; infected stocks are therefore maintained by mating infected females to males from a 'maintainer' line of uninfected flies. Typically, the infected line is established by injecting females from the maintainer line with spiroplasmas. Maintainer and infected lines are therefore assumed to be identical in the nuclear component of their genome but to differ in maternally inherited elements (e.g. spiroplasmas). With the exception of the HET stocks described below, all the Drosophila lines used in this study were inbred and established with one or a few females. 
Two spiroplasma types and four fly stocks were used. WSRO or 'willistoni sex ratio organisms', are male-lethal and have been cultured since the late 1950s in two $D$. willistoni cultures (W and Recife, or $\mathrm{R}$ ). Drosophila-spiroplasma associations are referred to by combining the fly stock and spiroplasma type designations: W-WSRO, for example, is the $D$. willistoni W line infected with WSROs. AROs or 'avirulent Recife organisms' are spontaneous non-male-lethal mutants that arose in the $\mathrm{R}$ line in 1979. As more fully described elsewhere (Ebbert, 1991) these mutants quickly swept the stock R-WSRO cultures: no WSROinfected flies were found after just a few generations. Uninfected flies from this culture were established as the AR line and AROs were maintained in both AR and $\mathrm{W}$ hosts.

There is a long history of spiroplasma work on artificial Drosophila hosts providing insight into the native interaction (reviewed in Williamson \& Poulson, 1979), demonstrating, for example, that while the male-lethal trait is virtually invariable regardless of host genetic background, considerable within- and between-species variation occurs in other aspects of the interaction phenotype. Here, I used $D$. pseudoobscura, not known to be infected with spiroplasmas in natural populations, as an artificial host. A standard isofemale line (Pinion Normal, or P) was infected with WSROs in the early 1960 s by injecting uninfected females with W-WSRO haemolymph. Throughout over 200 generations in culture, P-WSRO females have always been mated with $\mathrm{P}$ males, and have consistently produced all-female broods.

Infected ('host') and uninfected ('nonhost') flies were paired in five combinations in laboratory populations. In four of these pairs, both hosts and nonhosts had the same nuclear genetic background: W and W-WSRO, $A R$ and AR-ARO, W and W-ARO, and $P$ and P-WSRO lines. In the fifth set of populations, chromosomal variation among hosts was introduced to determine its effect on population dynamics. A genetically heterogeneous stock of $D$. willistoni (designated HET) was established using approximately equal numbers of individuals from matings between eight inbred lines: AR, R, W (described above and in Ebbert, 1991), one line from females collected in 1973 at Runaway Caves, Jamaica, two lines from females collected in 1984 near Rio de Janeiro, Brazil, and two from females collected in 1985 at Wingfield Estates, St. Kitts. W and W-WSRO females were mated to males from these eight lines and their offspring used to establish the experimental populations. This procedure was repeated for both HET populations.

\section{Life history and transmission rate studies}

Protocols for $D$. pseudoobscura fitness and transmission rate studies followed those previously described for D. willistoni (Ebbert, 1991) with two exceptions. First, all experiments were conducted at $20-21^{\circ} \mathrm{C}$, the temperature at which the $\mathrm{P}$ and P-WSRO stocks had been cultured. Secondly, because developmental time in $D$. pseudoobscura is longer than in $D$. willistoni, vials containing the broods of individual females were censused later, at 22 days. Pilot life history trait experiments in $D$. pseudoobscura were conducted as described earlier for D. willistoni (Ebbert, 1991).

\section{Population experiments}

The percentage of infected females was followed in 16 experimental populations started with varying ratios of infected to uninfected flies; some starting ratios were repeated over two experiments. Populations were established with 450 females in the desired ratio and 450 males. In the WSRO populations, all males came from uninfected stocks; in the ARO populations males were taken from infected and uninfected stocks in the same proportion as were females. These 900 flies were divided between three half-pint bottles with standard Drosophila media. To determine whether sex affected survival under these conditions, the sex ratio of uninfected $\mathrm{W}$ and $\mathrm{P}$ control populations was followed. Generations were discrete: after 10 days, parental adults were discarded. Their offspring were counted and sexed shortly after they eclosed. The next generation was started by combining offspring from all three bottles and distributing them evenly into each of three new population bottles. Periodically (every generation initially) females were scored for spiroplasma infection using dark field microscopy.

Spiroplasma infection rates in some species of Drosophila decline with temperature (Malogolowkin, 1959; Williamson \& Poulson, 1979). Therefore, populations were kept at a constant temperature: $23^{\circ} \mathrm{C}$ for the W-WSRO:W and W control populations and $21^{\circ} \mathrm{C}$ for the D. pseudoobscura populations. The HET and ARO populations, however, were subject to unintentional temperature fluctuations. These nine populations were moved from $23^{\circ} \mathrm{C}$ incubators to room temperature $\left(22-26^{\circ} \mathrm{C}\right)$ at generation 17 for population 13 (see Table 3 for population designations), 11 for both HET-WSRO populations, 7 for population 10 and generation 8 for the other five populations. Three generations later, they were moved to a $20-22^{\circ} \mathrm{C}$ incubator. They were returned to room temperature after one generation because population 
12 showed a sharp decline in the level of infected females.

All $D$. pseudoobscura populations were terminated by freezing when an incubator failed. $D$. willistoni populations were discontinued when the percentage of infected flies was estimated to be less than one, or after 20 generations. When a sample of 300 females (207 in population 4) proved negative for infection, the exact binomial probability that the population had a true infection rate of 1 per cent or greater ( 1.5 per cent for population 4 ) was less than 0.05 , and the population was discontinued.

\section{Statistical analysis}

Life history traits and transmission rate parameters in $D$. pseudoobscura were analysed as previously described for $D$. willistoni (Ebbert, 1991). Life history data were log transformed prior to analysis. Data were collected over several experiments and pooled (ANOVA showed no significant differences in any variable between experiments) with one exception: data from the two pilot experiments, where lifespan was limited to 40 days, were excluded from analysis of lifespan. Sterility rates, overall sex ratios and transmission rates were compared using both exact binomial probability tests and $\chi^{2}$ tests of independence. Two-tailed probability tests were used throughout.

In experimental populations, changes in the percentage of infected females were analysed using linear regression. Data on percentage infected females and sex ratio (percentage females) were transformed using the angular transformation. Two models using 'percentage infected females' as a dependent variable were analysed: one used number of generations as the independent variable, the other used sex ratio. The error in the estimation of the sex ratio was smaller, about 1-3 per cent (based on the binomial approximation of standard error), than the average binomial error of the infection rate ( 4 per cent, $n=169$, $\mathrm{SD}=2.9$, range $1-17$ per cent, average sample size of 65 females; note that, for clarity, errors are not graphed in Figs 2 and 3). Sex ratio was therefore chosen as the independent variable in the second set of regressions.

\section{Results}

\section{Life history traits in D. pseudoobscura}

Other than the loss of sons, there were no negative effects of infection on any of the fitness components measured. Production of daughters and lifespan variables (Table 1) were unaffected by infection (ANova, $F<0.4$ in all cases, $P>0.05$ ). About one of every four females was sterile: 11 of 50 uninfected females ( 22 per cent) and nine of 31 infected females (29 per cent); the sterility rates are not significantly different $(P>0.05$, exact binomial probability test). Sex ratio (percentage females) in the uninfected line was slightly female-biased: 51.5 per cent $(9308$ of 18080$)$ of the offspring counted were females, significantly higher than the expected 50 per cent (Pearson $\chi_{1}^{2}=8.0$, $P<0.01)$. The various fitness measures were positively correlated: Pearson correlation coefficients were 0.93 for number of daughters vs. reproductive lifespan, 0.73 for number of daughters vs. overall lifespan, and 0.83 for the two lifespan variables.

The number of daughters produced per 3 day brood peaked in mothers aged 6-18 days, and then declined sharply (Fig. 1). Neither P nor P-WSRO females produced offspring in the first 3 days after eclosion. These data are similar to previous per brood estimates of fecundity (number of eggs) in D. pseudoobscura (Matzke \& Druger, 1977). As with some D. willistoni-spiroplasma interactions (Ebbert, 1991), repeated measures ANOVA suggested a shift towards earlier production of daughters in the first 15 days of life in spiroplasma hosts. Infection status did not affect the overall production of daughters (between subject $F$-test was not significant), but did show a significant interaction with time (namely, infection affects the pattern of daughter production over time; within subject analysis, $\left.F_{3,189}=3.36, P=0.017\right)$. Inspection of Fig. 1 suggests that infected females produce more

Table 1 Estimates of lifetime fecundity and lifespan (number of days) in infected ( $\mathrm{P}$ WSRO) and uninfected (P) Drosophila pseudoobscura

\begin{tabular}{lcc}
\hline & P-WSRO & P \\
& $\bar{x}(n, \mathrm{SE}$, max $) \dagger$ & $\bar{x}(n, \mathrm{SE}, \max ) \dagger$ \\
\hline No. of daughters & $178(31,30,540)$ & $211(50,28,734)$ \\
Total progeny & $178(31,30,540)$ & $410(50,55,1395)$ \\
Lifespan & $36(20,5,72)$ & $38(44,4,90)$ \\
Reproductive lifespan & $19(20,4,48)$ & $25(44,3, \quad 66)$ \\
\hline
\end{tabular}

$\dagger$ Average (sample size, standard error and maximum). 


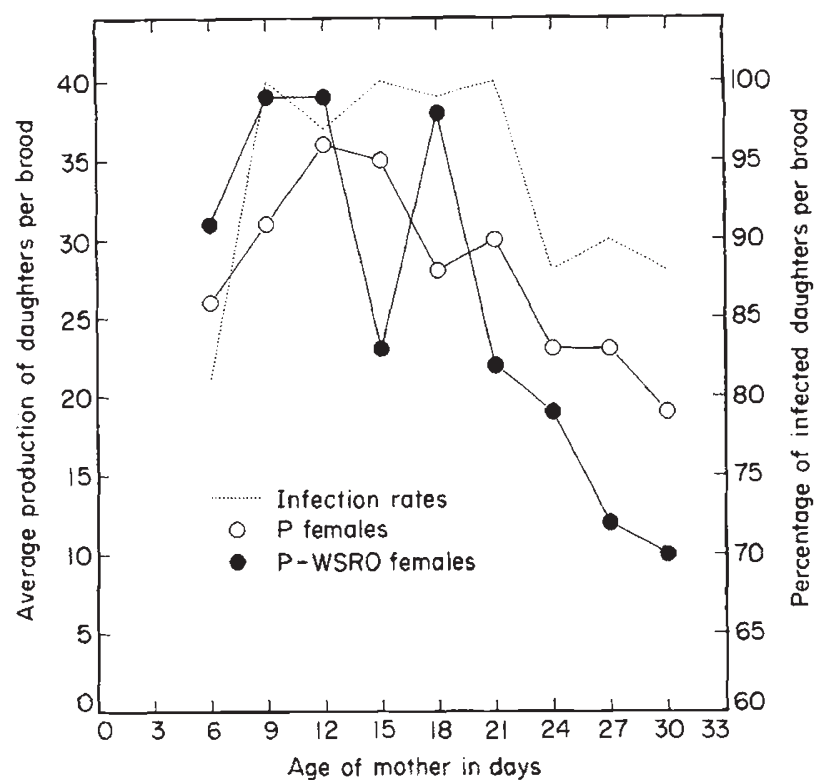

Fig. 1 Average number of daughters produced by infected (P-WSRO) and uninfected (P) Drosophila pseudoobscura females, and infection rates for daughters of infected females, over successive 3-day broods. Standard errors averaged 3.6 $(\mathrm{SD}=0.8$, range $2-5)$ for $\mathrm{P}$ and $5.9(\mathrm{SD}=1.1$, range $5-8)$ for P-WSRO. See text for standard errors on infection rates.

offspring earlier in life. However, Tukey tests comparing each of the first three census days showed no difference $(P>0.05$ in all cases) between hosts and nonhosts in number of daughters produced.

\section{Transmission rates in D. pseudoobscura}

Overall transmission rates were lower than in WSROinfected D. willistoni (Ebbert, 1991). Of 1135 daughters sampled, 1035, or $91 \pm 1$ per cent, were infected. Success in infecting daughters varied with age, with the highest rates of spiroplasma transmission coinciding with the peak of offspring production (Fig. 1; errors on these rates average 2.4 per cent, range $0.3-7$ per cent, based on an average sample size of 89 females). Mothers aged less than 6 and older than 21 days infected significantly fewer daughters ( 329 of 388 ; $85 \pm 2$ per cent) than mothers between these ages $(470$ of $474 ; 99$ per cent \pm 0.05 ; comparing observed 85 per cent infected to expected 99 per cent infected, Pearson $\left.\chi_{1}^{2}=52.3, \quad P<0.001\right)$. Similar variation with age occurred in two D. willistoni lines (Ebbert, 1991).

\section{Predicted population dynamics}

Predictions of the relative rate of increase of infected and uninfected flies were made by estimating individual contributions $\left(F^{\prime}\right)$ to population growth (Lenski \&
Table 2 Mean, standard deviation and maximum (minimum is 0 in all cases) contributions to population growth $\left(F^{\prime}\right)$ for individuals in Drosophila willistoni and D. pseudoobscura lines, from eclosion to 15 days old

\begin{tabular}{lrrr}
\hline Lines & Mean & SD & Max \\
\hline AR $(n=44)$ & & & \\
$\quad$ Corrected & 5.7 & 5.4 & 25.0 \\
$\quad$ Uncorrected & 4.4 & 5.0 & 23.4 \\
AR-ARO $(n=48)$ & & & \\
$\quad$ Corrected & 6.8 & 6.4 & 23.7 \\
$\quad$ Uncorrected & 8.0 & 7.9 & 28.7 \\
P $(n=43)$ & & & \\
$\quad$ Corrected & 5.8 & 4.8 & 18.8 \\
$\quad$ Uncorrected & 5.3 & 4.6 & 18.1 \\
P-WSRO $(n=22)$ & & & \\
$\quad$ Corrected & 5.6 & 4.7 & 14.8 \\
$\quad$ Uncorrected & 6.6 & 5.5 & 17.8 \\
W $(n=48)$ & 10.9 & 11.5 & 42.0 \\
W-WSRO $(n=38)$ & 12.8 & 9.2 & 32.5 \\
W $(n=48)$ & 11.4 & 11.6 & 42.8 \\
W-ARO $(n=42)$ & 7.9 & 9.5 & 33.0 \\
\hline
\end{tabular}

Where maternal transmission rates are low, 'corrected' estimates discount the contribution of infected females (see text for details).

Service, 1982). Per brood survival and fecundity data from individual females in uncrowded conditions (Ebbert, 1991 and this paper) were used in the calculations. Individual contributions were then compared using ANOVA to determine whether they were affected by infection. In two cases (the comparisons between $P$ and P-WSRO and between AR and AR-ARO females) infected females produced more than 5 per cent uninfected daughters in their first broods. In effect, then, infected females were adding to the contribution of uninfected females to the population. To account for this, the fecundity of each infected female in her first brood was reduced to either 0.78 (for AR-ARO females) or 0.81 (P-WSRO females) of the original value (these discount factors correspond to the maternal transmission rates in the first brood). The number of daughters subtracted from the infected cohort was totalled, then divided evenly among the first broods of all nonsterile uninfected females. Estimates of $F^{\prime}$ were then made using these altered data sets, yielding the 'corrected' values in Table 2 .

Data for the first 15 days of adulthood were used in these calculations. In $D$. willistoni, adults eclosed about 12 days after the start of the oviposition period, and new populations were established an average of 25 days after oviposition by parental females $(\mathrm{SD}=6.5$, range 15-46 days). In $D$. pseudoobscura, adults eclosed in about 20 days, and new populations were 
established an average of 33 days after parental oviposition ( $\mathrm{SD}=5.7$, range 24-48 days.) In both species, then, parental females typically ranged from just eclosed to age 13 days. I assumed that the majority of eggs that survived to adulthood were laid in the first few days of the 10-day oviposition period: Gilpin (1974) has demonstrated a clear advantage for Drosophila embryos produced during the first 48 hours of egg-laying in laboratory populations. Therefore, fecundity schedules for females up to 15 days old best reflect the reproductive potential of the parental generation.

Comparing each pair of lines (i.e. infected and uninfected females) used to establish each population showed infection had an effect on $F^{\prime}$ values in only one case. Therefore, the relative percentage of infected and uninfected females should remain about constant in mixed populations, assuming that the selective factors at work in uncrowded culture vials are similar to those affecting host fitness in crowded population bottles. In the one exception, AR-ARO $F^{\prime}$ values, uncorrected for the poor AR-ARO transmission rates in the first brood, were higher than those of AR females $\left(F_{1,90}=6.56, P=0.012\right)$.

\section{Observed population dynamics}

The fate of infected females followed one of three patterns. In $D$. willistoni, females infected with malelethal spiroplasmas quickly dropped out of the population (Fig. 2a,b). The slopes ( $m$ in Table 3 ) of all the regressions of percentage infected females over time in the $D$. willistoni-WSRO populations were significantly different than zero, and negative. In contrast, the frequency of $D$. willistoni females infected with nonmale-lethal spiroplasmas (Fig. 2c,d) and D. pseudoobscura females infected with WSROs (Fig. 3) either declined slowly or remained constant. Half of these ten populations had slopes not significantly different from zero, and half had negative slopes which tended to be much less steep than those in the $D$. willistoni-WSRO populations.

Spiroplasma hosts were consistently at or near 100 per cent of the sampled flies in three populations (populations 7, 15 and, for the first 10 generations, population 12). Below about 95 per cent infection rates, hosts in ARO and D. pseudoobscura populations tended to decline. The decline of infected females in population 12 began when the population was exposed to lower temperatures and may have resulted from a temporary decrease in maternal transmission rates. However, the other populations exposed to these lower temperatures did not show a similar decline.

In three cases host frequency increased in populations which otherwise showed a general host decline. As transmission rates can vary with maternal age (e.g. Fig. 1), sampling unusually young or old females for spiroplasmas could produce an artificially low estimate of infection rates. However, in these three cases, the females assayed were of average age with respect to other cohorts sampled. Other explanations for these unexpected increases include chance and the use of unusually young or old females to start a population,
Fig. 2 Percentage of infected Drosophila willistoni females in laboratory populations over successive generations (see Table 3 for population designations). (a) W-WSRO:W populations 1 (open circles), 2 (filled circles), 3 (open triangles) and 4 (closed triangles). (b) HET-WSRO:HET populations 5 (open circles) and 6 (filled circles). (c) AR-ARO:AR populations 7 (open circles), 8 (filled circles), 9 (open triangles) and 10 (closed triangles). (d) W-ARO:W populations 11 (open circles), 12 (filled circles) and 13 (open triangles).
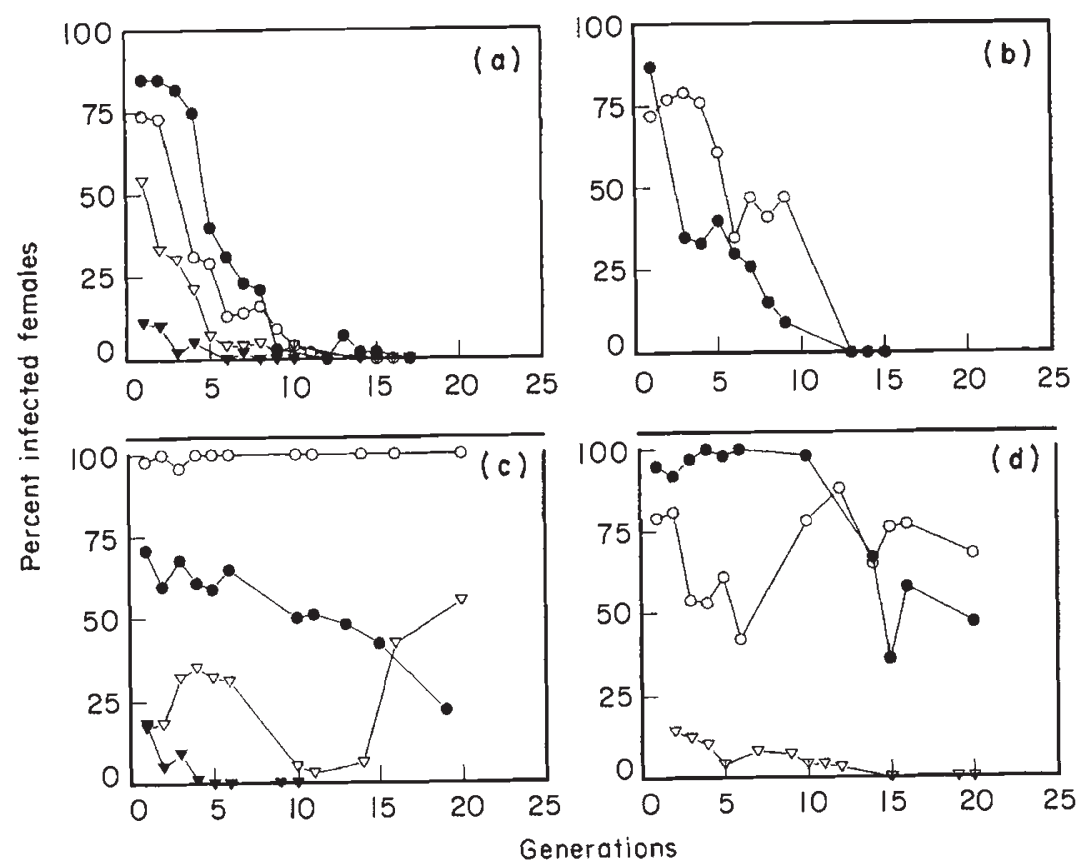
Table 3 Regression statistics for Drosophila willistoni and D. pseudoobscura populations

\begin{tabular}{|c|c|c|c|c|c|c|}
\hline \multirow[b]{2}{*}{ Population } & \multicolumn{3}{|c|}{$\%$ infected vs. time } & \multicolumn{3}{|c|}{$\%$ infected vs. SR } \\
\hline & $m$ & $r^{2}$ & $P$ & $m$ & $r^{2}$ & $P$ \\
\hline \multicolumn{7}{|c|}{ W-WSRO:W populations } \\
\hline $19: 1(\mathrm{~A})$ & -2.9 & 0.84 & $* * *$ & 2.3 & 0.80 & $* * *$ \\
\hline $29: 1(\mathrm{~B})$ & -4.2 & 0.85 & $* * *$ & 2.5 & 0.88 & $* * *$ \\
\hline $31: 1(\mathrm{~A})$ & -2.3 & 0.81 & $* * *$ & 2.9 & 0.41 & * \\
\hline $41: 9(\mathrm{~A})$ & -2.2 & 0.79 & $* *$ & 1.1 & 0.19 & NS \\
\hline \multicolumn{7}{|c|}{ HET-WSRO:HET populations } \\
\hline $59: 1(\mathrm{~A})$ & -5.0 & 0.91 & $* * *$ & 2.4 & 0.62 & ** \\
\hline $69: 1(\mathrm{~B})$ & -4.3 & 0.91 & $* * *$ & 2.4 & 0.87 & *** \\
\hline \multicolumn{7}{|c|}{ AR-ARO:AR populations } \\
\hline $79: 1(\mathrm{~A})$ & 0.3 & 0.23 & NS & -0.2 & 0.00 & NS \\
\hline $89: 1(\mathrm{~B})$ & -1.3 & 0.88 & $* * *$ & -0.6 & 0.14 & NS \\
\hline $91: 9(\mathrm{~A})$ & 0.3 & 0.02 & NS & -1.0 & 0.27 & NS \\
\hline $101: 9$ (B) & -2.5 & 0.67 & * & 3.9 & 0.81 & * \\
\hline \multicolumn{7}{|c|}{ W-ARO:W populations } \\
\hline $119: 1(\mathrm{~A})$ & 0.3 & 0.06 & NS & 0.8 & 0.10 & NS \\
\hline $129: 1(\mathrm{~B})$ & -2.5 & 0.70 & ** & -0.5 & 0.01 & NS \\
\hline $131: 1(\mathrm{~A})$ & -1.2 & 0.89 & $* * *$ & 0.3 & 0.02 & NS \\
\hline \multicolumn{7}{|c|}{ P-WSRO:P populations } \\
\hline $149: 1(\mathrm{~A})$ & -1.6 & 0.45 & NSt & 0.8 & 0.48 & NS $\ddagger$ \\
\hline $159: 1(\mathrm{~B})$ & -0.4 & 0.05 & NS & 0.2 & 0.01 & NS \\
\hline $161: 1(\mathrm{~A})$ & -1.7 & 0.74 & ** & -0.4 & 0.05 & NS \\
\hline
\end{tabular}

$\dagger P=0.07$.

$\ddagger P=0.06$.

Slopes $(m)$ and coefficients of determination $\left(r^{2}\right)$ are given for linear equations estimating the relationship between percentage infected females and either time (number of generations) or sex ratio (SR, percentage females). $P$ values are for the null hypothesis that the slopes are zero: ${ }^{*} P \leqslant 0.05,{ }^{* *} P \leqslant 0.01,{ }^{* * *} P \leqslant 0.001$.

thereby changing the reproductive potential of the parental cohort.

In population 9 , the percentage of infected females increased from 6 per cent (binomial error, $\mathrm{BE}=4$ ) in generation 14 to 42 per cent $(B E=7)$ in generation 16 ; this increase persisted until the population was discontinued. The average generation time in this culture was 23 days $(\mathrm{SD}=5.9)$, but five of the last seven generations were established with younger (less than 19-day-old) females. Young AR-ARO females may produce more daughters in their first broods than nonhosts, and may have therefore had a temporary advantage in this culture (Ebbert, 1991; although note that in Table 2 there is no difference between AR and AR-ARO females in individual rates of increase once corrections are made for imperfect maternal transmission). Use of younger females did not contribute to unexpected increases in either of the other two cases,

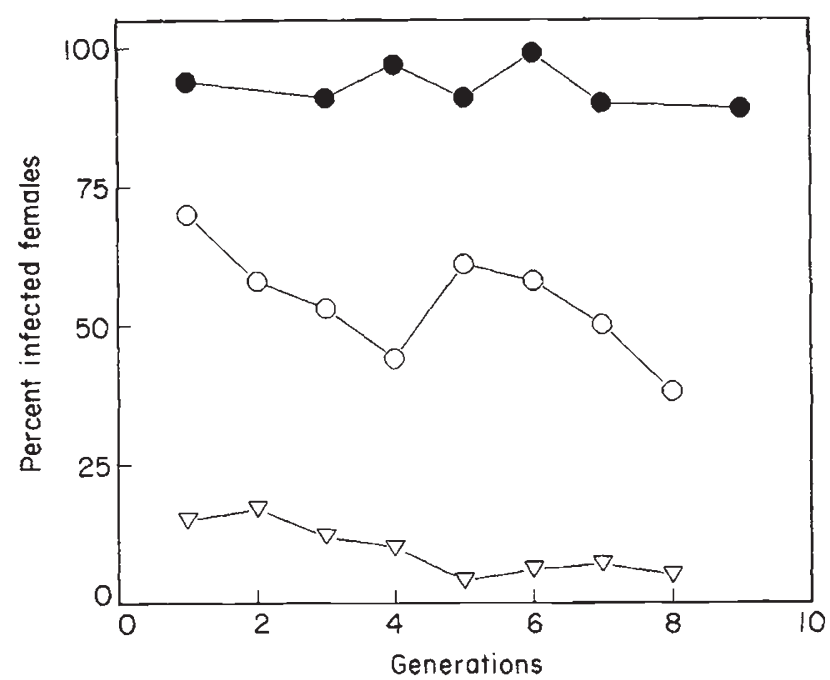

Fig. 3 Percentage of Drosophila pseudoobscura females infected with male-lethal spiroplasmas in laboratory populations over successive generations (see Table 3 for population designations): population 14 (open circles), 15 (filled circles) and 16 (open triangles).

and these increases were temporary. In population 11 , the percentage of infected females almost doubled, from 42 per cent $(B E=11)$ to 78 per cent $(B E=6)$, between generations 6 and 10. Drift may account for this increase: the average number of founders used in this population was $99(\mathrm{SD}=36)$, but generations 8 and 9 were founded with only 35 and 56 females per bottle. In population 14 , the increase in infected females between generations 4 and 5 (from 44 per cent to 61 per cent, $\mathrm{BE}=5$ for both) was not because of changes in the number or age of female founders and is therefore unexplained.

Only a fraction of the embryos produced each generation emerged as adults, suggesting strong selection, especially on larvae. The number of founders (females) averaged about 300 per generation, divided among three bottles (average per bottle $103, \mathrm{SD}=38$, range $15-178$, harmonic mean $=83$ ). The average number of offspring counted per generation was 643 ( $\mathrm{SD}=331$, range 70-2054). Assuming, conservatively, an average fertility of 50 eggs per female over a 10-day oviposition period (about half that produced in 15 days under uncrowded conditions; Fig. 1 and Ebbert, 1991), each generation's females could have produced about 15000 offspring, but at most only 7 per cent of that, about 1000 , actually emerged as adults.

\section{Sex ratios in experimental populations}

There was a significant positive correlation between the percentage of infected females and the sex ratio (percent females) in five of the six D. willistoni-WSRO 
populations, but only one of the seven ARO populations showed a similar relationship (Table 3). This suggests that the slight bias towards females in the broods of uncrowded AR-ARO females (Ebbert, 1991) was not apparent in AR-ARO populations. A positive relationship between infection rate and sex ratio was expected in the $D$. pseudoobscura populations, but no clear evidence for this was found (Table 3 ). If, however, the data for these three populations are pooled, there is a significant slope $\left(m=1.7, r^{2}=0.90\right.$, $P<0.001)$.

In five of the seven ARO populations and in the $D$. willistoni control, overall sex ratios were not significantly biased. In the two exceptions, sex ratios were slightly male-biased: 47.0 per cent females in population 8 ( 5170 of 11008; Pearson $\chi_{1}^{2}=20.3, P<0.001$ ), and 46.7 per cent females in population 11 (4596 of 9833; $\left.\chi_{1}^{2}=20.9, P<0.001\right)$. In the $D$. pseudoobscura control, the sex ratio was female-biased, 54.8 per cent (1726 of 3148), both when compared with an expected sex ratio of 50 per cent $\left(\chi_{1}^{2}=14.7, P<0.001\right)$ and the expected sex ratio of 51.5 per cent seen in individual $P$ females $\left(\chi_{1}^{2}=7.0, P<0.01\right)$

\section{Discussion}

Individual rates of increase were similar for infected and uninfected females and therefore, unless infection changes host response to crowding or the presence of nonhosts, neither should have had an advantage in mixed populations. The dynamics of the WSRO populations clearly deviated from this prediction. Under crowding, then, spiroplasma infection can have a negative effect on host fitness. The dynamics of the ARO and D. pseudoobscura populations were less clear-cut: hosts declined slowly in some populations while they persisted in others. As a whole, these results suggest that negative effects of crowding on host fitness, if they occur in these lines, are less than those on the $D$. willistoni-WSRO interaction. Population dynamics varied with the frequency of infected females: hosts tended to persist in populations with high (near 100 per cent) rates of infection, but declined in populations with lower infection rates.

Female fitness changes, then, depending on the type of spiroplasma they host; similar conclusions can be drawn from studies of individual females (Ebbert, 1991). Host line also affects individual fitness components in uncrowded conditions (Ebbert, 1991), but had no effect on population dynamics in either male-lethal or non-male-lethal infections.

Negative effects of spiroplasma infection on host fitness might have many proximate causes and stem ultimately from either stress or direct competitive interactions. Mechanisms by which Drosophila larvae succeed in laboratory cultures include increased feeding rate and larval tolerance of 'biotic residues', and decreased developmental time and weight needed to pupate; these vary with frequency, genotype and species (see, for example, Lewontin \& Matsuo, 1963; Bakker, 1969; Budnick \& Brncic, 1976; Bottella et al., 1985; Curtsinger \& Sheen, 1991 and references therein). Effects of spiroplasma infection on all these factors are possible: changes in insect physiology as a result of pathogen infection (e.g. increases in haemolymph carbohydrate levels) are well documented (Thompson, 1993). Spiroplasmas acidify culture media (reviewed in Chen \& Davis, 1979) and may reduce the $\mathrm{pH}$ of plant phloem (Vega, 1992). Reducing host haemolymph $\mathrm{pH}$ may induce other physiological changes with wide ranging consequences for host behaviour.

The very high densities of spiroplasmas in adult Drosophila haemolymph, particularly in $D$. willistoni (Williamson, 1969), might also affect adult fitness under stress. In both ARO and D. pseudoobscura hosts, internal populations of bacteria in adults appear less dense than in $D$. willistoni (personal observations under dark field microscopy); these flies may be less susceptible to stressful conditions than the more heavily infested $D$. willistoni WSRO hosts.

The rapid decline of $D$. willistoni females infected with WSROs is similar to earlier results with $D$. melanogaster infected with male-lethal spiroplasmas from D. nebulosa (Fitz-Earle \& Sakaguchi, 1986) and $D$. bifasciata infected with a male-lethal element (Ikeda, 1970). The decline of $D$. bifasciata females was the result, at least in part, of a competitive disadvantage in infected larvae (Ikeda, 1970). The persistence and slow decline of infected $D$. pseudoobscura females in mixed populations is the first indication that malelethal spiroplasmas can be maintained in laboratory populations.

While the line of $D$. pseudoobscura studied here was tolerant of male-lethal spiroplasmas, in both $D$. melanogaster (Sakaguchi \& Poulson, 1963; Counce \& Poulson, 1966) and D. willistoni (Ebbert, 1991), the phenotype of the WSRO-Drosophila interaction varies significantly between inbred lines. Thus, different lines of $D$. pseudoobscura would probably give different results. In $D$. melanogaster and $D$. pseudoobscura, transmission rates were erratic, especially in early broods, but $D$. melanogaster females occasionally produced uninfected sons (Williamson, 1965; Counce \& Poulson, 1966). Uninfected daughters in broods without sons in the artificial host $D$. robusta prompted Williamson $(1966,1969)$ to speculate that the killing 
agent might be separable from spiroplasmas (e.g. a virus). Subsequent work did not reveal clear differences between viruses in male-lethal and non-malelethal spiroplasmas (Cohen et al., 1987; see also discussion in Ebbert, 1991), but the possibility remains that lethality in the spiroplasma-Drosophila interaction may be a property of a second transmissible agent.

The evidence regarding a shift towards early reproduction in $D$. pseudoobscura (Fig. 1) was ambiguous: although repeated measures ANOVA indicated that the differences in the shape of the fecundity curves were significant, this conclusion was not borne out by comparing individual census days. Further work with a larger sample size is needed to determine whether artificial hosts show the same improved early reproduction as native hosts.

\section{Female fitness and spiroplasma persistence in the field}

Spiroplasma infection rates are about 5 per cent in affected populations of the $D$. willistoni group (Williamson \& Poulson, 1979). I summarize here studies of Drosophila ecology that are relevant to the problem of whether resource release, avoidance of inbreeding, horizontal transmission, larval crowding, early reproduction or some combination of these factors might account for this persistence.

While conditions necessary to promote parasite fitness via resource release or avoidance of inbreeding may exist in some populations, the available evidence suggests that the male-lethal trait alone does not account for the persistence of the bacteria in Drosophila populations. The Drosophila which breed in fallen fruits are a guild, limited in choices of oviposition site by stage of fruit decomposition rather than by species of fruit or yeast (see, for example, Dobzhansky \& Paven, 1950; Birch \& Battaglia, 1957; da Cuhna et al., 1957; Valente \& Araujo, 1985, 1986b; Valente et al., 1989). Breeding sites are therefore clusters of ripening fruits, attractive to individuals from many different species, patchily distributed in both time and space. A wide range of breeding site studies of neotropical Drosophila has shown that fruits from which more than about five adults emerge generally harbour more than one species, and as many as ten species are routinely recorded emerging from a single fruit (e.g. Dobzhansky \& Paven, 1950; Petersen, 1960; Pipkin, 1965; Bizzo \& Sene, 1982; Franck \& Valente, 1985; Valente \& Araujo, 1986b, 1991; Valente et al., 1989 and references therein). As most fruits harbour no flies, larvae are highly aggregated in the field (Burla et al., 1950; Atkinson \& Shorrocks, 1984).
There is strong evidence, then, that when the only larvae in a fruit are sibs, they are likely to enjoy an abundance of resources and, where they do not, that they will be in competition for those resources with the offspring of unrelated conspecifics and the larvae of other species. Thus, in crowded conditions, resources released by the death of sons will probably be available to nonsibs as well as sibs, and this suggests that resource release is unlikely to be a consistent or important factor in the maintenance of spiroplasma infections. Escape from inbreeding depression may be important in some circumstances (for example, as $D$. willistoni populations dwindle over the winter; see below). But given the aggregated distribution of eclosing adults, sibs are unlikely to be limited to sibs for matings. Sib $\times$ sib inbreeding thus appears to be unusual; however, to the extent that it occurs it can be a severe detriment to fitness: $D$. willistoni suffer a 25 per cent reduction in fitness as a result of sib-mating (Malogolowkin-Cohen et al., 1964; similar values are reported for other Drosophila species, Hedrick, 1985).

As noted in the Introduction, horizontal transmission (e.g. via feeding or vectors) remains a plausible and largely unexplored explanation for spiroplasma persistence. In laboratory experiments conducted primarily with $D$. hydei, larvae can be reared feeding solely on the carcasses of adult Drosophila and other insects, and congregating larvae appear to use 'social digestion' to dissolve chitin and cellulose (Gregg et al., 1990). Spiroplasma infection rates in affected $D$. hydei populations are much higher, about 40 per cent, than the 5 per cent typically reported for male-lethal infections (Ota et al., 1979; Williamson \& Poulson, 1979). These high rates of infection may be maintained by horizontal transmission mediated by larval feeding on dead, infected adults.

If these phenomena occur in willistoni group species (Gregg et al., 1990, argue that these behaviours are widespread in Drosophila and other dipterans) they may have implications for the persistence of malelethal infections beyond providing a possible route for horizontal transmission. If larvae eat the carcasses of eggs and young larvae as well as those of adults, and if larvae which feed on insect tissues and microorganisms are more robust than those feeding only on microorganisms, then dead eggs may be an important source of nutrition for larvae even when other resources are not limited. Spiroplasmas that kill male eggs would thus provide a benefit to their sisters, as in Adalia bipunctata (Hurst et al., 1992, 1993). Where only a single brood feeds in a fruit these benefits would accrue primarily to infected sisters. However, because larvae tend to aggregate, in fruits with unrelated broods, benefits to spiroplasmas might be reduced or eliminated. 
The results reported here and previously (Ebbert, 1991) suggest a disadvantage for infected flies under crowded conditions but a possible benefit to some spiroplasma hosts in early reproductive effort. Because both studies are limited by the use of laboratory stocks, these results need to be confirmed using fresh isolates of spiroplasmas and Drosophila. Assuming they can be, it is clear that these effects may be important in the persistence of infected flies during the seasonal fluctuation of Drosophila populations.

D. willistoni has a tremendous geographical range, from the southern United States to northern Argentina, and throughout this range the dry season, with its extremes of heat and cold, affects population dynamics of $D$. willistoni and other members of the fruit-breeding guild (e.g. Dobzhansky \& Paven, 1950; Petersen, 1960; Pipkin, 1965; Bizzo \& Sene, 1982; Franck \& Valente, 1985; Valente \& Araujo, 1986a, 1991; Valente et al., 1989). Abundance (both in terms of numbers of individuals and relative representation) in $D$. willistoni typically peaks in the rainy season (when it is often the most common species) and sharply declines over the dry season (frequently to less than 5 per cent).

The implications of this seasonal variation are many, and the ecological factors that influence persistence of spiroplasma hosts are likely to change or even be reversed as the season and the biotic environment change. For example, the yearly exponential population boom in $D$. willistoni will increase the importance of any advantage in early reproduction to infected flies and, later in the season, increase the probability that flies will encounter crowded conditions. If cold temperatures reduce maternal transmission rates in the field, as suggested by Malogolowkin (1959) and Williamson \& Poulson (1979), any benefit to infection over the rainy months may be lost during the winter.

Fitness in natural populations of $D$. willistoni may be largely a matter of enduring the dry season and spiroplasma infection may influence overwintering survival. Leafhoppers (Dalbulus maidis) infected with Spiroplasma kunkelii are more tolerant of overwintering conditions in the laboratory than are their uninfected conspecifics, under cool (Ebbert \& Nault, 1994) and possibly under warm conditions (M. A. Ebbert \& L. R. Nault, unpublished data). We argue that these spiroplasmas which infect maize, an annual, probably rely on Dalbulus leafhoppers both as vectors and as overwintering sites. Hackett et al. (1992) suggest that group XIV spiroplasmas might overwinter in lampyrid beetles.

In Drosophila, transovarial transmission and lack of pathogenic effects on overwintering females may be an overwintering strategy of the bacteria, and increased survival of infected Drosophila under dry season conditions might explain their persistence despite imperfect transmission. A number of authors have argued that lethality is ancestral in interactions between insects and mollicutes (Gold \& Sylvester, 1982; Purcell, 1982; Nault et al., 1984; Hammond \& Hardy, 1988; Hackett \& Clark, 1989; Whitcomb \& Hackett, 1989; Purcell \& Nault, 1991). Haemolymph infections by mollicutes tend to have negative effects on host fitness (suggesting that the initial Drosophilaspiroplasma interaction was also negative) and, with no route out of the host, haemolymph infections are also detrimental to bacterial fitness. However, given the ability to infect other hosts from the haemolymph (as with invasion of host eggs in maternally inherited infections), adaptation to the haemolymph habitat not only allows ready access to new hosts but also provides protection from environmental extremes. In the Drosophila-spiroplasma association, if adaptation to transovarial transmission involved detecting and reducing negative effects on the transmitting host (females), a benign interaction with females would result, leaving negative effects on males intact as an ancestral trait. Spiroplasma adaptation to vertical transmission in $D$. hydei may have evolved via selection against negative effects on hosts regardless of sex.

It should be clear from the above discussion that these and similar arguments (see, Ebbert, 1993; Hurst \& Majerus, 1993) are based on generalizations about host ecology and thus cannot be used to dismiss completely any factor in the persistence of a male-lethal infection. Unusual or even rare events can play a role in the persistence of an infection (as in, for example, the rare horizontal transmission event to a new species). Furthermore, these general arguments are limited by our ignorance of virtually all aspects of the population biology of male-lethal infections and there is no direct evidence that any particular fitness benefit to hosts is responsible for the maintenance of any infection in natural populations. While male-lethal infections are intriguing in their own right, they are also significant as model systems in the study of host-parasite interactions and sex ratio modification, and as potential biological control agents. Detailed field and laboratory experiments which test the assumptions of the resource release and inbreeding avoidance models, explore horizontal transmission and female fitness effects, vary host density and environmental conditions, document the incidence and persistence of lethal and non-malelethal pathogens in the field, and take into account genetic variation in both symbionts are urgently needed to improve our understanding of the ecology and evolution of these important insect pathogens. 


\section{Acknowledgements}

Discussions with K. Hackett, L. Nault, R. Stouthamer, $\mathrm{J}$. Werren and $\mathrm{R}$. Whitcomb on the population dynamics of endosymbionts and their hosts strongly influenced the development of this paper; K. Hackett also commented on an earlier version. I thank $R$. Lenski for pointing out the applicability of individual contributions to rates of increase to this data set. I also thank my doctoral committee (J. R. Powell, advisor, L. Buss, R. DeSalle and R. Vaisnys) for comments and advice on the design and interpretation of these experiments, which were conducted in partial fulfillment of the Ph.D. requirements at Yale University. I wish particularly to thank J. R. Powell and the late Donald F. Poulson, both of Yale University, for training and Drosophila stocks. The research was supported by grants to J. R. Powell and by an Ender's research grant to M.A.E.

\section{References}

ATKINSON, W. D. AND SHORROCKS, B. 1984. Aggregation of larval diptera over discrete and ephemeral breeding sites: the implications for coexistence. Am. Nat., 124, 336-351.

BAKKER, K. 1969. Selection for rate of growth and its influence on competitive ability on larvae of Drosophila melanogaster. Neth. J. Zool., 19, 541-595.

BANKS, C. J. 1956. Observations on the behaviour and mortality in Coccinellidae before dispersal from the egg shells. Proc. R. Ent. Soc. Lond., 31, 56-60.

BIRCH, L. C. AND BatTaglia, B. 1957. The abundance of Drosophila willistoni in relation to food in natural populations. Ecology, 38, 165-166.

BIZZO, N. M. V. AND SENE, F. M. 1982. Studies of the natural populations of Drosophila from Peruibe (SP), Brazil (Diptera, Drosophilidae). Rev. Brasil. Biol., 42, 539-544.

BOTELLA, L. M., MOYA, A., GONZÁLEZ, M. C. AND MÉNSUA, J. L. 1985. Larval stop, delayed development and survival in overcrowded cultures of Drosophila melanogaster: effect of urea and uric acid. J. Insect Physiol., 31, 179-185.

BUDNIK, M. AND BRNCIC, D. 1976. Effects of larval biotic residues on viability in four species of Drosophila. Evolution, 29, 777-780.

BURLA, H., dA CUNHA, A. B., CAVAlCANTI, A. G. L., DOBZHANSKY, TH. AND PAVAN, C. 1950. Population density and dispersal rates in Brazilian Drosophila willistoni. Ecology, 31, 393-404.

CAMPBELL, в. C. 1989 . On the role of microbial symbiotes in herbivorous insects. In: Bernays, E. A. (ed.) Insect-Plant Interactions, pp. 1-44. CRC Press, Boca Raton, FL.

CARVAlHO, G. G. AND dA CRUZ, M. P. 1962. Transfer of the 'sexratio' factor in Drosophila willistoni by ingestion. Science, 138, 52.

CHEN, T. A. AND DAVIS, R. E. 1979. Cultivation of spiroplasmas. In: Whitcomb, R. F. and Tully, J. G. (eds) The Mycoplasmas, vol. 3, pp. 65-82. Academic Press, New York.
COHEN, A. J., WILliAMSON, D. L. AND OISHI, K. 1987. SpV3 viruses of Drosophila spiroplasmas. Isr. J. Med. Sci,, 23, 429-433.

COUNCE, S. J. AND POULSON, D. F. 1966. The expression of maternally-transmitted sex ratio condition (SR) in two strains of Drosophila melanogaster. Genetica, 37, 364-390.

CURTSINGER, J. W. AND SHEEN, F.-M. 1991. Frequency-dependent viability in mutant strains of Drosophila melanogaster. J. Hered., 82, 105-109.

dA CUNHA, A. B., SheHATA, A. M. E. AND dE OLIVEIRA, W. 1957. A study of the diets and nutritional preferences of tropical species of Drosophila. Ecology, 38, 98-106.

DOBZHANSKY, TH. AND PAVAN, C. 1950. Local and seasonal variations in relative frequencies of species of Drosophila in Brazil. J. Anim. Ecol., 19, 1-14.

EBBERT, M. A. 1991. The interaction phenotype in the Drosophila willistoni-spiroplasma symbiosis. Evolution, 45, 971-988.

EBBERT, M. A. 1993. Endosymbiotic sex ratio distorters in insects and mites. In: Wrensch, D. L. and Ebbert, M. A. (eds) Evolution and Diversity of Sex Ratio in Insects and Mites, pp. 150-191. Chapman and Hall, New York.

EBBERT, M. A. AND NAULT, L. R. 1994. Improved overwintering ability in Dalbulus maidis (Homoptera: Cicadellidae) vectors infected with Spiroplasma kunkelii (Mycoplasmatales: Spiroplasmataceae). Environ. Ent., 23, 634-644.

FINE, P. E. M. 1978. On the dynamics of symbiote-dependent cytoplasmic incompatibility in Culicine mosquitoes. $J$. Invert. Path., 30, 10-18.

FITZ-EARLE, M. AND SAKAGUCHI, B. 1986. Sex ratio distortion in populations and its possible role in insect suppression; experimental studies with strains of Drosophila melanogaster carrying cytoplasmically-inherited male-killing spiroplasmas. Jap. J. Genet., 61, 447-460.

FRANCK, G. AND VALENTE, V. L. S. 1985. Study of the fluctuation in Drosophila populations of Bento Goncalves, RS, Brazil. Rev. Brasil. Biol., 45, 133-141.

GILPIN, M. 1974. Intraspecific competition between Drosophila larvae in serial transfer systems. Ecology, 55, 1154-1159.

GOLD, R. E. AND SYLVEster, E. S. 1982. Pathogen strains and leafhopper species as factors in the transmission of Western $\mathrm{X}$-disease agent under varying light and temperature conditions. Hilgardia, 50, 1-43.

GREGG, T. G., McCRATE, A., REVEAL, G., HALL, S. AND RYPSTRA, A. L. 1990. Insectivory and social digestion in Drosophila. Biochem. Genet., 28, 197-207.

HACKETT, K. J. AND CLARK, T. B. 1989. The ecology of spiroplasmas. In: Whitcomb, R. F. and Tully, J. G. (eds) The Mycoplasmas, vol. 5, pp. 113-200. Academic Press, New York.

HACKETT, K. J., WHITCOMB, R. F., TULLY, J, G., LLOYD, J. E, ANDERSON, J. J., ClARK, T. B., HENEGAR, R. B., ROSE, D. L., ClARK, E. A. AND VAUGHN, J. L.. 1992. Lampyridae (Coleoptera): a plethora of mollicute associations. Microbial Ecol., 23, 181-193.

HAMMOND, A. M. AND HARDY, T. N. 1988. Quality of diseased plants as hosts for insects. In: Heinrichs, E. A. (ed.) Plant Stress-Insect Interactions, pp. 381-432. John Wiley and Sons, New York. 
HEDRICK, P. w. 1985. Genetics of Populations. Jones and Bartlett Publishers, Boston, MA.

HEMPTINNE, J.-L., DIXON, A. F. G. AND COFFIN, J. 1992. Attack strategy of ladybird beetles (Coccinellidae): factors shaping their numerical response. Oecologia, 90, 238-245.

HURST, G. D. D. AND MAJERUS, M. E. N. 1993. Why do maternally inherited microorganisms kill males? Heredity, 71, 81-95.

HURST, G. D. D., MAJERUS, M. E. N. AND WALKER, L. E. 1992. Cytoplasmic male killing elements in Adalia bipunctata (Linnaeus) (Coleoptera: Coccinellidae). Heredity, 69, 84-91.

HURST, G. D. D., MAJERUS, M. E. N. AND WALKER, L. E. 1993. The importance of cytoplasmic male killing elements in natural populations of the two spot ladybird, Adalia bipunctata (Linnaeus) (Coleoptera: Coccinellidae). Biol. J. Linn. Soc., 49, 195-202.

IKEDA, н. 1970 . The cytoplasmically-inherited "sex-ratio" condition in natural and experimental populations of Drosophila bifasciata. Genetics, 65, 311-333.

LENSKI, R. E. AND SERVICE, P. M. 1982. The statistical analysis of population growth rates calculated from schedules of survivorship and fecundity. Ecology, 63, 655-662.

LEWONTIN, R. C. AND MATSUO, Y. 1963. Interaction of genotypes determining viability in Drosophila busckii. Proc. Natl. Acad. Sci. U.S.A., 49, 270-278.

MADDEN, L. V., NAUUT, L. R., HEADY, S. E. AND STYER, W. E. 1984. Effect of maize stunting mollicutes on survival and fecundity of Dalbulus leafhopper vectors. Ann. appl. Biol., 105, 431-441.

MALOGOLOWKIN, C. 1959. Temperature effects on maternally inherited "sex-ratio" conditions in Drosophila willistoni and Drosophila equinoxialis. Am. Nat., 93, 365-368.

MALOGOLOWKIN-COHEN, C., LEVENE, H., DOBZHANSKY, N. P. AND SIMMONS, A. s. 1964. Inbreeding and the mutational and balanced loads in natural populations of Drosophila willistoni. Genetics, 50, 1299-1311.

MALOGOLOWKIN-COHEN, C. AND RODRIGUES-PEREIRA, M. A. Q. 1975. Sexual drive of normal and SR flies of Drosophila nebulosa. Evolution, 29, 579-580.

MATZKE, M. A. AND DRUGER, M. 1977. Evolutionary divergence between two populations of Drosophila pseudoobscura. Evolution, 31, 597-602.

MILLS, N. J. 1982. Voracity, cannibalism and coccinellid predation. Ann. Appl. Biol., 101, 144-148.

NAULT, L. R., MADDED, L. V., STYER, W. E., TRIPLEHORN, B. W.. SHAMBaUGH, G. F. AND HEADY, S. E. 1984. Pathogenicity of corn stunt spiroplasma and maize bushy stunt mycoplasma to their vector, Dalbulus longulus. Phytopathology, 74, 977-979.

OTA, T., KAWABE, M., OISHI, K. AND POULSON, D. F. 1979. Nonmale killing spiroplasmas in Drosophila hydei. J. Hered., 70, 211-213.

OSAWA, N. 1989. Sibling and non-sibling cannibalism by larvae of a lady beetle Harmonia axyridis Pallas (Coleoptera: Coccinellidae) in the field. Res. Popul. Ecol., 31, 153-160.

PETERSEN, J. A. 1960. Studies on the ecology of the genus "Drosophila". I. Collections in two different life zones and seasonal variations in Rio Grande do Sul, Brazil. Rev. Brasil. Biol., 20, 3-16.

PIPKIN, s. B. 1965. The influence of adult and larval food habits on population size of neotropical ground-feeding Drosophila. Am. Midl. Nat., 74, 1-27.

PURCELL, A. H. 1982. Evolution of the insect vector relationship. In: Mount, M. S. and Lacy, G. H. (eds) Phytopathogenic Prokaryotes, vol. 1, pp. 121-156. Academic Press, New York.

PURCELL, A. H. AND NAULT, L. R. 1991. Interactions among plant pathogenic prokaryotes, plants and insect vectors. In: Barbosa, J. P., Krischik, V. A. and Jones, C. G. (eds) Microbial Mediation of Plant-Herbivore Interactions, pp. 383-405. Wiley Press, New York.

ROSEWELL, J. AND SHORROCKS, B. 1987. The implications of survival rates in natural populations of Drosophila: capture-recapture experiments on domestic species. Biol. J. Linn. Soc., 32, 373-384.

SAKAGUCHI, B. AND POULSON, D. F. 1963. Interspecific transfer of the "sex-ratio" condition from Drosophila willistoni to $D$. melanogaster. Genetics, 48, 841-861.

SHULL, A. F. 1948. An all-female strain of lady beetles with reversions to normal sex ratios. Am. Nat., 82, 241-251.

SKINNER, S. w. 1985. Son-killer: a third extrachromosomal factor affecting the sex ratio of the parasitoid wasp, Nasonia (=Mormoniella) vitripennis. Genetics, 109 , 745-759.

THOMPSON, S. N. 1993. Redirection of host metabolism and effects on parasite nutrition. In: Beckage, N. E., Thompson, S. N. and Federici, B. A. (eds) Parasites and Pathogens of Insects, vol. 1, pp. 125-144. Academic Press, New York.

UYENOYAMA, M. K. AND FELDMAN, M. w. 1978. The genetics of sex ratio distortion by cytoplasmic infection under maternal and contagious transmission: an epidemiological study, Theor. Pop. Biol., 14, 471-479.

VALENTE, V. L. S. AND ARAUJO, A. M. 1985. Observations on the chromosomal polymorphism of natural populations of Drosophila willistoni and its association with the choice of feeding and breeding sites. Revta Brasil. Genet., 8, 271-284.

valente, V. L. S. AND ARAUJo, A. M. 1986a. Chromosomal polymorphism, climatic factors, and variation in population size of Drosophila willistoni in southern Brazil. Heredity, 57, 149-159.

VALENTE, v. L. S. AND ARAUJo, A. M. 1986 b. Comments on breeding sites of Drosophila willistoni Sturtevant (Diptera, Drosophilidae). Revta Bras. Ent., 30, 281-286.

VALENTE, V. L. S. AND ARAUJO, A. M. 1991. Ecological aspects of Drosophila species in two contrasting environments in southern Brazil (Diptera, Drosophilidae). Revta Bras. Ent., 35, 237-253.

VALENTE, V. L. S., RUSZCZYK, A., SANTOS, R. A., BONORINO, C. B. C., BRUM, B. E. P., REGNER, L. AND MORALES, N. B. 1989. Genetic and ecological studies of urban and marginal populations of Drosophila in the south of Brazil. Evolucion Biologica, 3, 19-35.

VEGA. F. E. 1992. The Role of Plant Pathogens on the Biology and Ecology of Vector and non-Vector Insect Herbivores. 
Ph.D. Dissertation, University of Maryland, College Park, U.S.A.

WATSON, G. S. 1960. The cytoplasmic "sex-ratio" condition in Drosophila. Evolution, 14, 256-265.

WERREN, J. H. 1987. The coevolution of autosomal and cytoplasmic sex ratio factors. J. Theor. Biol., 124, 317-334.

WHITCOMB, R. F. AND HACKETT, K. J. 1989. Why are there so many species of mollicutes? An essay on prokaryote diversity. In: Knutson, L. and Stoner, A. K. (eds) Beltsville Symposia in Agricultural Research 13: Biotic Diversity and Germplasm Preservation, Global Imperatives, pp. 205-240. Kluwer Academic Publishers, Boston, MA.

WILliamson, D. L. 1965 . Kinetic studies of "sex-ratio" spirochetes in Drosophila melanogaster Meigen females. $J$. Invert. Path., 7, 493-501.

WILliAMSON, D. L. 1966. Atypical transovarial transmission of sex ratio spirochetes by Drosophila robusta Sturtevant. $J$. Exp. Zool., 161, 425-430.

WILliamson, D. L. 1969. The sex ratio spirochete in Drosophila robusta. Jap. J. Genet., 44, 36-41.

WILliamson, D. L. AND POULSON, D. F. 1979. Sex ratio organisms (spiroplasmas) of Drosophila. In: Whitcomb, R. F. and Tully, J. G. (eds) The Mycoplasmas, vol. 3, pp. 175-208. Academic Press, New York.

YAMADA, M., NAWA, S. AND WATANABE, T. K. 1982. A mutant SR organism (SRO) in Drosophila that does not kill the host males. Jap. J. Genet., 57, 301-305. 